\section{$\underset{\substack{\text { hommes } \\ \text { \& migrations }}}{ }$}

\section{Hommes \& migrations}

Revue française de référence sur les dynamiques

migratoires

$1315 \mid 2016$

Ondes de choc

\title{
La mécanique des flux
}

Documentaire français de 2016

\section{Nathalie Loubeyre}

\section{OpenEdition \\ 1 Journals}

\section{Édition électronique}

URL : http://journals.openedition.org/hommesmigrations/3723

DOI : 10.4000/hommesmigrations.3723

ISSN : 2262-3353

\section{Éditeur}

Musée national de l'histoire de l'immigration

\section{Édition imprimée}

Date de publication : 1 juillet 2016

Pagination : 94-95

ISBN : 978-2-919040-36-0

ISSN : 1142-852X

Référence électronique

Nathalie Loubeyre, «La mécanique des flux », Hommes \& migrations [En ligne], 1315 | 2016, mis en ligne le 02 janvier 2017, consulté le 15 septembre 2020. URL : http://journals.openedition.org/

hommesmigrations/3723 


\section{SPÉCIAL FRONTIÈRES}

\section{LA MÉCANIQUE DES FLUX \\ DOCUMENTAIRE FRANÇAIS DE NATHALIE LOUBEYRE (2016)}

Par NATHALIE LOUBEYRE, réalisatrice.

a " maîtrise des flux ", c'est la manière

Ld'appeler la politique migratoire de l'Europe. Au-delà de la violence de la métaphore, la formule a au moins le mérite de renvoyer ce mouvement migratoire, vieux comme le monde, du côté de son inexorabilité. Toute tentative de fermer les frontières de l'Europe exerce sur les migrants des violences aussi considérables qu'inefficaces. C'est cette violence cachée que le film fait apparaître. À travers plusieurs voix recueillies sur des lieux-clés des routes migratoires, celles des migrants comme celles de ceux qui les chassent, les soignent, les pleurent ou les enterrent. En faisant résonner ces voix dans les paysages des confins de l'Europe, en travaillant sur les traces des passages, en filmant la tentative de clôture, en convoquant les images de ces migrants "illégaux ", que renvoient les appareils de contrôle ou les caméras de télévision, la réalisatrice dessine par touches successives et de façon sensorielle cette violence que les médias escamotent, épuisent ou banalisent.

Le film suit néanmoins un fil et une progression. Il part d'une voix institutionnelle, celle de l'Europe, pour basculer vers celle des migrants et de ceux qui les croisent ou les accompagnent. Ces voix, parfois muettes, se font écho, prennent le relais les unes des autres. Elles se collectivisent, au fur et à mesure que ces derniers s'organisent en groupes de survie. Elles évoluent aussi dans leur contenu en racontant d'abord la violence de la traversée ou de l'« accueil », la mort, puis l'enfermement, la survie au quotidien, la détermination sans faille quels que soient les obstacles. Progressivement, elles adoptent un ton plus politique. Elles parlent du migrant érigé en bouc 
émissaire de la crise en Europe et pointent la responsabilité des Occidentaux dans ces migrations forcées. Au final, une inversion du regard permet aux migrants de nous regarder et de nous juger. Ces dix voix ont été mises en scène en fonction des situations dans lesquelles elles ont été recueillies et du statut des interlocuteurs. Elles sont presque toujours traitées en off quand il s'agit de personnes autres (garde-frontière, soignant, mufti) et en longs gros plans sur les visages des migrants. II s'agit de ré-humaniser ce "flux » et donc de donner à voir longuement ces visages que d'ordinaire on floute, gageant avec Levinas que le spectacle du visage de l'Autre contient une éthique.

Le territoire est filmé en fonction de sa capacité à évoquer à la fois l'identité européenne (bouts de paysage, fragments d'architecture, présence de drapeaux ou d'iconographie, vestiges historiques, églises), mais aussi le contexte actuel (crise économique, montée du nationalisme, mouvements sociaux). Les migrants sont toujours inscrits dans les paysages (nature, terre, ciel). Pour donner un côté plus vibrant à cette partition filmique, parfois âpre, la caméra est presque toujours à l'épaule, y compris pour capter les paysages ou le monde animal, pour inscrire ce mouvement de la migration dans un mouvement plus vaste. Les fleuves, et toutes sortes d'écoulements, permettent au film de reprendre la métaphore du flux migratoire, mais aussi du principe de vie, de façon à situer le mouvement des migrants dans le monde tel qu'il tourne et d'inclure ces lieux dans une cosmogonie européenne.

Plutôt que de filmer les murs là où ils existent, le film fait apparaître cette " clôture » invisible, mais néanmoins bien réelle, qui est la plus courante. C'est surtout par des patrouilles, policières ou militaires, qu'elle se signale. Le film fait apparaître l'agence Frontex autant que possible. Sans autorisation de filmer ses agents, le film a ainsi volé les images de certains agents de Frontex sur le terrain, reconnaissables à leurs brassards bleus lorsqu'ils étaient en opération avec les gardes-frontières nationaux, auprès desquels il était plus facile d'obtenir des autorisations. 